\title{
Deficiências e desequilíbrios minerais em bovinos e ovinos - revisão dos estudos realizados no Brasil de 1987 a $1998^{1}$
}

\author{
Carlos Hubinger Tokarnia ${ }^{2}$, Jürgen Döbereiner ${ }^{3}$, Sheila S. Moraes ${ }^{4}$ e Paulo Vargas \\ Peixoto $^{2}$
}

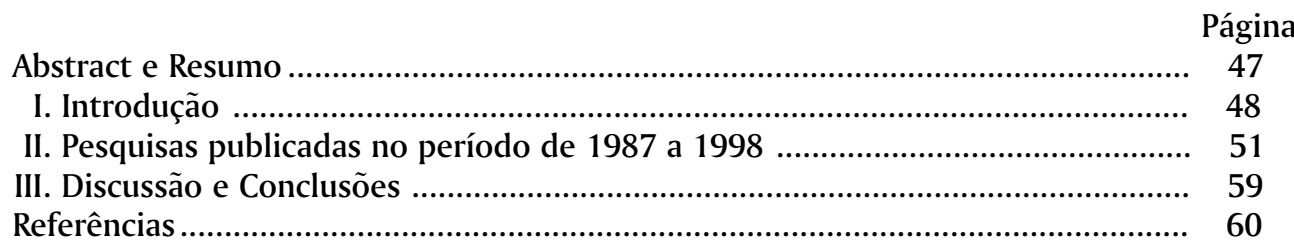

ABSTRACT.- Tokarnia C.H., Döbereiner J., Moraes S.S. \& Peixoto P.V. 1999. [Mineral deficiencies and imbalances in cattle and sheep - a review of Brazilian studies made between 1987 and 1998.] Deficiências e desequilíbrios minerais em bovinos e ovinos - revisão dos estudos realizados no Brasil de 1987 a 1998. Pesquisa Veterinária Brasileira 19(2):47-62. Projeto Sanidade Animal Embrapa/UFRRJ, Seropédica, RJ 23851-970, Brazil.

This review follows on from two previous ones on the subject covering the periods from 1943 to 1976 and 1976 to 1987 . They are all based on the chemical analyses of liver or other animal tissues or fluids and/or experimentation, complemented or not by analyses of pasture and soil samples. They do not include studies based only on chemical analyses of plant and soil samples. Regarding macroelements, noteworthy are the studies on phosphorus deficiency, the most important mineral deficiency shown previusly. Copper and cobalt deficiencies were the most frequent microelement deficiencies. There were several reports on copper poisoning in sheep. Subclinical deficiency of zinc was frequently verified. Subclinical manganese deficiency was rarely recognized and to the contrary, elevated values of this element occasionaly were found. There was little data on selenium, so its importance in Brazil remains unclear; nutritional miopathy was diagnosed for the first time in calves, but only once. Low iron values were found in the liver samples of cattle affected by enzootic hematuria. This is easily explained by the continuous loss of blood leading to severe anemia. High iron values were found in the liver samples from some areas; sometimes associated with low copper values.

Among the investigations made during the last decade, special mention should be made of two diseases in which the etiology has not yet been established. These are "ronca" (snoring disease) and "doença do peito inchado" (brisket disease), both of which have a chronic course in adult cattle. In "ronca", liver copper is very low and iron particularly high. Presumably the latter is caused by poor utilization due to the copper deficiency. In "doença do peito inchado", the liver values for manganese and cobalt were low and those for iron very high. In this case, the high iron probably comes from the severe liver congestion caused by the chronic cardiac insufficiency seen in this disease. Mention also should be made of "morte subita" (sudden

\footnotetext{
${ }^{1}$ Parte da palestra proferida pelo primeiro autor durante o Seminário Internacional sobre Deficiências Minerais em Ruminantes, realizado em 5 de junho de 1998, em Porto Alegre, Universidade Federal do Rio Grande do Sul e Conselho Regional de Medicina Veterinária do Rio Grande do Sul.

${ }^{2}$ Depto Nutrição Animal e Pastagens, Universidade Federal Rural do Rio
}

de Janeiro (UFFRJ), Km 47, Seropédica, RJ 23851-970; bolsistas do CNPq (305010/76-VT e 302342/86-VT).

${ }^{3}$ Projeto Sanidade Animal Embrapa/UFRRJ, Km 47, Seropédica, RJ 23851970; bolsista do CNPq (309294/88-1).

${ }^{4}$ Embrapa-Centro Nacional de Pesquisa de Gado de Corte, Rodovia BR 262 Km 4, Cx. Postal 154, Campo Grande, MS 79002-970. 
death) in cattle in the State of Rio Grande do Sul. In this case, liver copper levels were extremely low and no poisonous plant could be blamed. Congenital hypomyelinogenesis in calves was diagnosed in the same area.

The mineral deficiencies diagnosed during the period of this review are shown on a map, together with the respective bibliographic references.

INDEX TERMS: Mineral deficiencies, excesses of minerals, mineral toxicities, mineral imbalances, cattle, sheep, Brazil.

RESUMO.- É apresentada uma revisão dos estudos realizados no Brasil sobre distúrbios no metabolismo mineral em bovinos, sobretudo deficiências minerais, no período de 19871998. Esta revisão foi feita em continuação de duas revisões prévias sobre $o$ assunto, que abrangeram os períodos de 19431976 e 1976-1987. Nessas revisões são omitidos os estudos realizados apenas através de dosagens químicas de amostras de pastagem e de solo, sendo referidos aqueles baseados em análises de amostras de fígado ou outros tecidos ou fluidos dos animais e/ou experimentação, complementados ou não por análises químicas de pastagem e de solo. Em relação aos macroelementos, destacam-se os estudos sobre a deficiência de fósforo, já estabelecida anteriormente como a deficiência mineral mais importante no Brasil. Valores baixos de ferro em amostras de figado foram constatados em bovinos afetados pela hematúria enzoótica, o que é compreensível, já que os animais apresentam marcada anemia devido a perda contínua de sangue. Destacaram-se, por outro lado, os valores elevados de ferro em diversas regiões; em algumas delas foi demonstrado que os níveis desse elemento estavam associados a valores baixos de cobre. As deficiências de cobre e cobalto foram as mais frequentes entre as de microelementos. Diversas ocorrências de intoxicação por cobre em ovinos foram comunicadas. A deficiência subclínica de zinco tem sido verificada com bastante frequência. A deficiência subclínica de manganês foi raramente constatada; ao contrário, houve verificações de valores elevados deste elemento. Em relação ao selênio, os dados continuam escassos, insuficientes para se saber qual a importância da deficiência desse elemento em bovinos e ovinos no Brasil; a miopatia nutricional em bezerros foi diagnosticada uma única vez. Entre os estudos realizados neste último período devem ser mencionados, especialmente, aqueles que abordam duas doenças cuja etiologia ainda não foi estabelecida, vulgarmente conhecidas como "ronca" e "doença do peito inchado", ambas de evolução crônica, afetando bovinos adultos. Na enfermidade conhecida como "ronca", os valores hepáticos de cobre são muito baixos e os de ferrro extremamente altos; deve-se considerar a hipótese de que os níveis hepáticos de ferro estão muito elevados em decorrência da sua não-utilização em função da deficiência de cobre. Na "doença do peito inchado", os valores hepáticos de manganês e de cobalto são baixos e os de ferro são muito elevados; é possível que as alterações nos níveis hepáticos de ferro sejam apenas o reflexo do acúmulo de sangue no fígado, uma vez que essa enfermidade é caracterizada por insuficiência cardíaca crônica que cursa com acentuada congestão hepática. Ainda deve ser destaca- da, no Rio Grande do Sul, a ocorrência de "morte súbita" em bovinos, cujos valores hepáticos para cobre foram muito baixos; nenhuma planta tóxica pode ser responsabilizada por essas ocorrências. Nesta mesma área, a hipomielinogênese congênita em bovinos foi diagnosticada. A ocorrência das deficiências minerais diagnosticadas durante o período correspondente a esta revisão foram lançadas em um mapa, com as respectivas referências bibliográficas.

TERMOS DE INDEXAÇÃO: Deficiências minerais, excessos de minerais, intoxicação por minerais, desequilíbrios minerais, bovinos, ovinos, Brasil.

\section{INTRODUÇÃO}

Uma revisão sobre os estudos das deficiências e dos desequilíbrios minerais em bovinos e ovinos realizados no Brasil até 1976, consta no trabalho apresentado no Simpósio LatinoAmericano sobre Pesquisa em Nutrição Mineral de Ruminantes em Pastagens, Belo Horizonte, MG, 1976 (Tokarnia \& Döbereiner 1976, 1978). (Fig. 1)

Revisão sobre as deficiências e os desequilíbrios minerais em bovinos e ovinos diagnosticadas no Brasil entre 1976 e 1987, pode ser encontrada no trabalho apresentado na Reunião sobre Determinação de Carências e Suplementação Mineral em Bovinos, Campo Grande, MS, 1987 (Tokarnia et al. 1988). (Fig. 2)

Na presente trabalho apresenta-se um levantamento das pesquisas sobre deficiências e desequilíbrios minerais em bovinos e ovinos no Brasil, realizadas entre 1987 e 1998. Excepcionalmente incluimos dois trabalhos que não foram mencionados nas revisões anteriores, bem como alguns outros relativos à deficiência de selênio, anteriores a $1987^{5}$.

De acordo com o propósito dessas revisões, são omitidos os estudos realizados apenas através de dosagens químicas de amostras de pastagem e de solo, sendo referidos aqueles baseados em análises de amostras de fígado, de outros tecidos ou de fluidos dos animais e/ou na experimentação, complementados ou não por analises químicas de pastagem e de solo. Alguns trabalhos, que relatam estudos experimentais sobre o efeito benéfico geral da administração de misturas minerais, sem especificação dos minerais, também não foram incluídos.

\footnotetext{
${ }^{5}$ Em relação aos artigos em que mais do que um mineral foi enfocado pelo(s) autor(es), sempre foi fornecido um delineamento do trabalho na primeira vez que ele é mencionado nesta revisão; em relação aos outros minerais que aparecem em seguida, nesses trabalhos, são então fornecidos somente os dados específicos para aquele elemento.
} 
Fig.1. Deficiências minerais diagnosticadas no Brasil até 1976. Os números em parênteses indicam a fonte de informação obtida da seguinte literatura:

(l) Bauer A.C., Santos A.G. \& Mancuso P.C. 1964. Algumas observações sobre uma doença de bovinos no município de Santa Vitória do Palmar. III Conf.Soc.Vet.Rio Grande do Sul, Porto Alegre, p.153-161. - (2) Corrêa R. 1955. Carência de cobalto em bovinos no Estado de São Paulo. Revta Bras.Biologia 15:309-313. - (3) Corrêa R. 1957. Carência de cobalto em bovinos. Arqs Inst.Biológico, S.Paulo, 24:199-227. - (4) Dayrell M.S., Döbereiner J. \& Tokarnia C.H. 1973. Deficiência de fósforo em bovinos na região de Brasília. Pesq.Agropec.Bras., Sér.Vet.8:105-114 - (5) Gióvine N. 1943. Estudo clínico da deficiência de fósforo nos bovinos de Minas Gerais. Arqs Esc.Vet., Belo Horizonte, 1:17-25, 7 fig. - (6) Guimarães J.M.A.B. \& Nascimento C.N.B. 1971. Efeito da suplementação mineral sobre a percentagem de nascimentos de bezerros em rebanhos de bovinos de corte na llha de Marajó. Série: Estudos sobre Bovinos, IPEAN, Belém, Pará, vol.1(no.2), p.37-51. - (7) Grunert E. \& Santiago C. 1969. Über den Einfluss von Knochenfuttermehl auf die Fruchtbarkeit von Fleischrindern in Rio Grande do Sul, Brasilien. Zuchthyg.4:65-71. - (8) Iglesias F.A. 1951. Caatingas e chapadões. Sér. 5a. Brasiliana, vol.271. Biblioteca Pedagógica Brasileira, Editora Nacional, São Paulo, p.357-363. - (9) Macedo J.N. 1952. Fazendas de gado no vale de São Francisco. Documentário da Vida Rural no.3, SIA, Min.Agricultura, Rio de Janeiro. - (10) Megale F. 1949a. Sobre a incidência de esterilidade em vacas no Estado de Minas Gerais. Arqs Esc.Vet., Belo Horizonte, 2:17-27. - (11) Megale F. 1949b. Contribuição ao estudo do bócio congênito nos bezerros, no Estado de Minas Gerais. Arqs Esc.Vet., Belo Horizonte, 2:143-150. - (12) Menicucci Sobrinho L. 1943. Carência de fósforo e cálcio nos bovinos. Arqs Esc.Vet., Belo Horizonte, 1:9-15. - (13) Santos V.T. \& Pereira Neto E. 1963. II Reunião de Zootecnia e Veterinária, Bagé, Rio Grande do Sul, p.63. - (14) Soares L.C. 1963. Guia de Excursão no.8, realizada por ocasião do XVIII Congr.Int.Geogr., Conselho Nacional de Geografia, Rio de Janeiro, p.304. - (15) Sutmöller P., Abreu A.V., Grift J.van der \& Sombroek W.G. 1966. Mineral imbalances in cattle in the Amazon valley. Communication no.53, Dep.Agric.Res., Amsterdam. 135 p. + tables. - (16) Tokarnia C.H., Canella C.F.C. \& Döbereiner J. 1960. Deficiência de cobre em bovinos no delta do Rio Parnaíba, nos Estados do Piauí e Maranhão. Arqs Inst.Biol.Animal, Rio de J., 3:25-37. - (17) Tokarnia C.H., Canella C.F.C., Guimarães J.A. \& Döbereiner J. 1968. Deficiências de cobre e cobalto em bovinos e ovinos no Nordeste e Norte do Brasil. Pesq.Agropec.Bras.3:35l-360. - (18) Tokarnia C.H., Canella C.F.C., Guimarães J.A., Döbereiner J. \& Langenegger J. 1970. Deficiência de fósforo em bovinos no Piauí. Pesq.Agropec.Bras.5:483-494. - (19) Tokarnia C.H. \& Döbereiner J. 1978. Observações próprias, em: Diseases caused by mineral deficiencies in cattle raised under range conditions in Brazil, p.163-169. In: Conrad J.H. \& McDowell L.R. (ed.) Latin American Symposium on Mineral Nutrition Research with Grazing Ruminants, Belo Horizonte, Brazil. - (20) Tokarnia C.H., Döbereiner J., Canella C.F.C. \& Dâmaso M.N.R. 1961. Deficiência de cobalto em bovinos na Serra da Ibiapaba, no Estado do Ceará. Arqs Inst.Biol.Animal, Rio de J., 4:195-202. - (21) Tokarnia C.H., Döbereiner J., Canella C.F.C. \& Guimarães J.A. 1966. Ataxia enzoótica em cordeiros na costa do Piauí. Pesq.Agropec.Bras.1:357-382. - (22) Tokarnia C.H., Guimarães J.A., Canella C.F.C. \& Döbereiner J. 1971. Deficiência de cobre e cobalto em bovinos e ovinos em algumas regiões do Brasil. Pesq.Agropec.Bras., Sér.Vet.6:61-77. 
Fig. 2. Deficiências minerais diagnosticadas no Brasil de 1976 a 1987. Os números em parênteses indicam a fonte da informação obtida da seguinte literatura:

(1) Barros N.N., Teixeira L.B., Moraes E., Canto A.C. \& Italiano E.C. 1981. Teores de minerais no complexo solo-planta-animal de áreas de terras firmes do Amazonas. Comunicado Técnico no.16/81, Embrapa-UEPAE de Manaus. 3 p. - (2) Camargo W.V.A., Fernandes N.S. \& Santiago A.M.H. 1976. Pesquisa de minerais em bovinos no nordeste de Mato Grosso. Anais XV Congr.Bras.Med.Vet., Rio de Janeiro, p.194-195. Resumo. - (3) Camargo W.V.A., Fernandes N.S. \& Santiago A.M.H. 1980. Estudos de elementos minerais de interesse pecuário em regiões da Amazônia Legal. Arqs Inst.Bilógico, S.Paulo, 47(4):83-111. - (4) Camargo W.V.A., Santiago A.M.H., Nazário W. \& Chiba S. 1985. Teores de minerais de interesse pecuário em regiões da Polamazônia. Revta Bras.Med.Vet., Rio de J., 7(4):118-124. - (5) Fernandes N.S., Santiago A.M.H., Camargo W.V.A. \& Vianna S.S.S. 1976. Níveis estacionais de cobre e de cobalto em tecido animal e vegetal. Atualidades Veterinárias, Porto Alegre, 5(28):24-27. - (6) Lopes H.O.S., Fichtner S.S., Jardim E.C., Costa C.P. \& Martins Jr W. 1980a. Composição mineral de amostras de solo, forragem e tecido animal da micro-região Mato Grosso de Goiás. I. Cálcio, fósforo, magnésio e potássio. Arqs Esc.Vet. UFMG, Belo Horizonte, 32(2):161-174. - (7) Lopes H.O.S., Fichtner S.S., Jardim E.C., Costa C.P. \& Martins Jr W. 1980b. Teores de cobre e zinco em amostras de solos, forrageiras e tecido animal da micro-região Matro Grosso de Goiás. Arqs Esc.Vet.UFMG, Belo Horizonte, 32(2):151-159. - (8) Lucci C.S., Moxon A.L., Zanetti M.A., Schalch E., Pettinati R.L., Fukushima R.S., Franzolin Neto R. \& Marcomini D.G. 1983. Selênio em rebanhos leiteiros do Estado de São Paulo. I. Níveis de selênio em soros sanguíneos - nota prévia. Anais XX Reunião Anual da SBZ, Pelotas, RS, p.197. - (9) Mendes M.O. 1977. Mineral status of beef cattle in the northern part of Mato Grosso, Brazil, as indicated by age, season, and sampling technique. Dissertation, University of Florida, Gainesville. 236 p. - (10) Moraes S.S. 1986. Untersuchungen zu Abhängigkeiten der Zink-, Mangan- und Selengehalte in Lebern von Rindern aus ausgewählten Regionen Brasiliens. Dissertation, Hannover. 146 p. - (11) Moraes E., Italiano E.C. \& Pieniz L.C. 1982. Efeito de níveis de fósforo no crescimento e engorda de bovinos mantidos em pastagem de quicuio da Amazônia. Pesquisa em Andamento no.36, Embrapa, UEPAE de Manaus. 4 p. - (12) Souza J.C., Conrad J.H., Blue W.G. \& McDowell L.R. 1979. Inter-relações entre minerais no solo, plantas forrageiras e tecido animal. 1. Cálcio e fósforo. Pesq.Agropec.Bras. 14(4):387-395. - (13) Sousa J.C., Conrad J.H., McDowell L.R., Ammerman C.B. \& Blue W.G. 1980. Inter-relações entre minerais no solo, forrageiras e tecido animal. 2. Cobre e molibdênio. Pesq.Agropec.Bras. 15(3):335-341. - (14) Sousa J.C., Conrad J.H., Blue W.G., Ammerman C.B. \& McDowell L.R. 1981. Inter-relações entre minerais no solo, forrageiras e tecido animal. 3. Manganês, ferro e cobalto. Pesq.Agropec.Bras. 16(5):739-746. - (15) Sousa J.C., Conrad J.H., Mott G.O., McDowell L.R., Ammerman C.B. \& Blue W.G. 1982. Interrelações entre minerais no solo, plantas forrageiras e tecido animal no norte de Mato Grosso. 4. Zinco, magnésio, sódio e potássio. Pesq.Agropec.Bras. 17(1):11-20. - (16) Sousa J.C., Gomes R.F.C., Rezende A.M., Rosa I.V., Cardoso E.G., Gomes A., Costa F.P., Oliveira A.R., Coelho Neto L. \& Curvo J.B.E. 1983. Resposta de novilhos nelorados à suplementação mineral em pastagens de capim-colonião. Pesq.Agropec.Bras. 18(3):311-318. - (17) Sousa J.C., Gomes R.F.C., Silva J.M.S. \& Euclides V.P.B. 1985. Suplementação mineral de novilhos de corte em pastagens adubadas de capim-colonião. Pesq.Agropec.Bras. 20(2):259-269. - (18) Sousa J.C. \& Darsie G. 1985. Deficiências minerais em bovinos de Roraima, Brasil. I. Zinco e cobalto. Pesq.Agropec.Bras. 20(11):1309-1316. - (19) Sousa J.C., Gonçalves E.M., Viana J.A.C. \& Darsie G. 1986. Deficiências minerais em bovinos de Roraima, Brasil. III. Cálcio e fósforo. Pesq.Agropec.Bras. 21(12):13271336 . 


\section{PESQUISAS PUBLICADAS DE 1987 A 1998 (Fig. 3)}

\section{Fósforo e cálcio}

Brum et al. (1987a,b) e Pott et al. (1987, 1989a,b,c,d,e) realizaram um levantamento das deficiências (e desequilíbrios) minerais de bovinos, nas sub-regiões de Paiaguás, Nhecolândia (parte central), Baixo Piquiri e Aquidauana no Pantanal Matogrossense. Nesse estudo foram coletadas amostras de solo e de forrageiras nativas em 3 a 5 unidades de paisagem (unidades geomórficas). Em relação a Paiaguás, as unidades de pastagem estudadas foram vazante, campo-cerrado e cordilheira, já no que se refere as outras sub-regiões, foram colhidas amostras de solo e forrageiras na mata, cerrado, coronal, campo limpo e lagoa, esta última ainda subdividida em lagoas de água doce (baías) e as de água salobra (salinas). Foram colhidas amostras de tecido animal (biopsia de fígado, soro sangüíneo obtido de sangue retirado por punção jugular, biopsia da $12^{\text {a }}$ costela ). Estas coletas eram realizadas duas a quatro vezes por ano, de acordo com as possibilidades, isto é, em agosto (período da seca), novembro (período inicial das chuvas), fevereiro (período de enchente) e maio (final da enchente e começo do período seco). Em Nhecolândia também foram coletadas amostras de água. Os animais utilizados no estudo eram vacas de corte, aneloradas, em lactação, mantidas nas mesmas invernadas onde foram coletadas as amostras de solo e forragem.

Através desse levantamento foi concluído (Brum et al. 1987a, Pott et al. 198, 1989b,d), em relação à sub-região dos Paiaguás, que o nível de Ca no solo foi baixo em todas as épocas do ano e em todas as unidades geomórficas estudadas e que as plantas forrageiras que crescem nas vazantes somente atendem as necessidades de $\mathrm{Ca}$, para vacas em lactação, no mês de agosto. Apesar desse fato, os animais só estiveram deficientes em Ca durante o mês de maio, fato que, de acordo com os autores, sugere que nas épocas em que não houve deficiência nos animais, esses as tenham suprido com outras forrageiras que não as estudadas. Esses autores determinaram que os níveis de $\mathrm{P}$ no solo eram constantemente baixos nas três unidades geomórficas, que as plantas forrageiras não atendiam às necessidades de $\mathrm{P}$ de vacas em lactação, e que os animais estiveram deficientes em $P$ em todas as épocas do ano, tomando-se como indicativo de deficiência o teor desse elemento no osso. Em relação à subregião Nhecolândia (parte central) determinou-se que os teores de Ca apresentaram-se baixos nos solos de cerrado, caronal, campo limpo e lagoa, porém seriam adequados para vacas em lactação nas gramíneas de mata; os níveis desse elemento, por outro lado, seriam insuficientes em agosto, até para vacas secas nas demais unidades, exceto no caronal. Os teores de Ca no soro sangüíneo mostraram-se normais em novembro, mas no limite inferior da normalidade em fevereiro, maio e agosto. Já os níveis de $\mathrm{P}$, médios nos solos de mata e muito baixos nas demais unidades, só seriam adequados para vacas em lactação, nas forrageiras de mata, porém nas demais unidades não alcançaram sequer as recomendações mínimas para vacas secas. Enquanto os teores séricos de $\mathrm{P}$ apresentaram-se no limite inferior da normalidade em fevereiro, os valores de Ca e P no osso foram baixos na amostragem de novembro, a única em que foram feitas as análises neste tecido. Os resultados do trabalho sugerem a possível ocorrência de deficiência combinada de Ca e P (e $\mathrm{Mg}$ ) na dieta dos bovinos, na área estudada. Em relação à sub-região Baixo Piquiri os autores chegaram a conclusão, que deficiências de Ca e P nela não são evidentes. Em relação à sub-região de Aquidauana, determinou-se que os solos apresentam baixos níveis de Ca e $\mathrm{P}$, que as plantas forrageiras apresentam baixos níveis de $\mathrm{P}$, que nos tecidos das vacas em lactação ocorreram níveis de Ca e $\mathrm{P}$ indicativos de deficiências destes nutrientes. Vide também $\mathrm{Mg}, \mathrm{K}, \mathrm{Na}, \mathrm{Fe}, \mathrm{Cu}, \mathrm{Zn}$ e Mn.

Guimarães et al. (1992) verificaram a variação sazonal de macro e microelementos (e de vitamina A), no capim, no plasma e no fígado de 24 novilhas Nelore mantidas em pastagem cultivada de Brachiaria decumbens, no município de Igarapé, área de cerrado na Zona Metalúrgica do Estado de Minas Gerais. $\mathrm{O}$ animais recebiam mistura mineral comercial à vontade. Amostras de capim eram colhidas a cada 15 dias. Mensalmente eram retiradas amostras de sangue de 20 novilhas e 4 animais eram necropsiados com coleta de amostras de fígado. A cada mês havia reposição dos 4 animais necropsiados. Os autores chegaram a conclusão que os baixos níveis de fósforo no capim, verificados durante as estações chuvosa e seca, caracterizam deficiência de $P$ na área pesquisada, apesar de as análises de $\mathrm{P}$ no plasma terem revelado níveis normais para bovinos de corte, nas duas estações do ano. Os autores comentam que a concentração de $P$ inorgânico no plasma é útil no diagnóstico de deficiência desse elemento, mas apresenta limitações, já que os teores de $P$ podem ser influenciados pelo estresse, exercício, hemólise, temperatura e tempo de separação do soro, citando Dayrell et al. (1973). Os teores de cálcio na pastagem não variaram significativamente durante as duas estações do ano, e foram considerados adequados para atender as exigências nutricionais dos bovinos. Vide também $\mathrm{Mg}$, Fe, $\mathrm{Cu}$ e $\mathrm{Zn}$.

Costa et al. (1992) observaram, através de experimento com suplementação de diversas misturas minerais a novilhos de engorda realizado em fazenda no município de Diamantina, Mato Grosso, que a mistura mineral englobando $\mathrm{NaCl}+\mathrm{P}+$ microelementos proporcionava os melhores ganhos médios de peso/animal. Análises das cinzas de ossos indicaram deficiência de $P$, enquanto as amostras de forrageiras demonstraram adicionalmente também deficiência de $\mathrm{Zn}$. Vide também $\mathrm{Zn}$.

Lisbôa et al. (1996) determinaram os níveis sorológicos de $\mathrm{Ca}, \mathrm{P}, \mathrm{Mg}$, Na, $\mathrm{Cl}$ e $\mathrm{K}$, os níveis hepáticos de $\mathrm{Fe}, \mathrm{Co}, \mathrm{Cu}, \mathrm{Zn}$ e Mn e o teor de Ca, P e Mg nos ossos de 32 bovinos acometidos por botulismo epizoótico em propriedades localizadas em muncípios próximos a Botucatu, São Paulo. Em relação ao Ca e ao $\mathrm{P}$, o estudo bioquímico sérico apontou hipocalcemia e hipofosfatemia como indicativo de deficiência de P. As dosagens no tecido ósseo mostraram concentrações normais de Ca e níveis discretamente reduzidos de $\mathrm{P}$ e de cinzas . Vide também $\mathrm{Mg}$, Na, Cl, K, Co, Cu. Zn e Mn.

Dayrell \& Resz (1984) realizaram, durante 12 meses, aná- 
Fig. 3. Deficiências e desequilíbrios minerais em bovinos e ovinos diagnosticados no Brasil de 1987 a 1998. A sete anteposta aos símbolos significa teores elevados do elemento em questão. Os números em parênteses indicam a fonte da informação obtida da seguinte literatura: (1) Barros C.S.L., Barros S.S., Santos M.N. \& Metzdorf L.L. 1988. Miopatia nutricional em bovinos no Rio Grande do Sul. Pesq.Vet.Bras.8(3/4):51-55. - (2) Bondan E.F., Riet-Correa F. \& Giesta S.M. 1991. Níveis de cobre em fígados de bovinos no sul do Rio Grande do Sul. Pesq.Vet. Bras.11(3/4):75-80. - (3) Brum P.A.R., Sousa J.C., Comastri Filho J.A. \& Almeida I.L. 1987a. Deficiências minerais de bovinos na sub-região dos Paiaguás, no Pantanal Mato-grossense. I. Cálcio, fósforo e magnésio. Pesq.Agropec.Bras.22(9/10):1039-1048. - (4) Brum P.A.R., Sousa J.C., Comastri Filho J.A. \& Almeida I.L. 1987b. Deficiências minerais de bovinos na sub-região dos Paiaguás, no Pantanal Mato-grossense. II. Cobre, zinco, manganês e ferro. Pesq.Agropec.Bras. 22(9/10):1049-1060. - (5) Costa J.B.D., Wolf G., Sousa J.C. \& Costa F.P. 1992. Suplementação mineral de novilhas neloradas em solo arenoso de mata e pastagens de capim-colonião. Pesq. Agropec.Bras.27(10):1459-1466. - (6) Dayrell M.S. \& Resz F. 1984. Teor de fósforo inorgânico no soro sanguíneo de vacas em lactação da região da Zona da Mata. Pesq.Agropec.Bras.19(10):1307-1312. - (7) Fichtner S.S., Paula A.N. \& Viana H.A. 1987. Determinação das carências minerais em bovinos no Estado de Goiás. I. Zinco, cobalto, ferro e manganês. Anais da XXIV Reunião Anual da SBZ, 26 a 31 de julho, Brasília, p. 145. Resumo. - (8) Guimarães A.M., Saliba E.O.S., Rodriguez N.M. \& Moreira P.K. 1992. Variação sazonal de vitamina A, macro e microelementos no capim, plasma e fígado de novilhas Nelore, criadas em pastagens de capim braquiária (Brachiaria decumbens). Arq.Bras.Med.Vet.Zootec.44(1):57-66. - (9) Lisbôa J.A.N., Kuchembuck M.R.G., Kohayagawa A., Bomfim S.R.M., Santiago A.M.H. \& Dutra I.S. 1996. Resultados de patologia clínica e dosagens de elementos minerais em bovinos acometidos pelo botulismo epizoótico no Estado de São Paulo. Pesq.Vet.Bras.16(4):91-97. - (10) Lucci C. S., Moxon A.L., Zanetti M.A., Fukushima R.S., Schalch E. \& Pettinati R.L. 1984a. Selênio em bovinos leiteiros no Estado de São Paulo. I. Níveis de selênio em soros sanguíneos. Revta Fac.Med.Vet.Zootec.USP, São Paulo, 21(1):65-70. - (11) Moraes S.S. 1986. Untersuchungen zu Abhängigkeiten der Zink-, Mangan- und Selengehalte in Lebern von Rindern aus ausgewählten Regionen Brasiliens. Dissertation, Hannover. 146p. - (12) Moraes S.S., Silva G.N. \& Döbereiner J. 1994. Microelementos minerais e a "cara inchada" dos bovinos. Pesq.Vet.Bras.14(1):25-33. - (13) Moraes S.S. 1998. Avaliação das concentrações de ferro, manganês e ferro no figado de bovinos e ovinos de várias regiões do Brasil. Pesq.Vet.Bras.18(3/4):107110.- (14) Moraes S.S., Tokarnia C.H. \& Döbereiner J. 1999. Deficiências de microelementos em bovinos e ovinos em algumas regiões do Brasil. Pesq.Vet.Bras. 19(1):19-33. - (15) Penna A.P., Virgens N.C., Bautista A.R.P.L., Rodrigues F.M., Silva W.G., Costa J.B. \& Suzart J.C.C. 1983. Interação da deficiência de zinco no elo forrageira-bovino, no município de Ipirá, Bahia. Anais da XX Reunião Anual da SBZ, Pelotas, RS. Resumo. - (16) Pott E.B., Brum P.A.R., Almeida I.L., Comastri Filho J.A. \& Dynia J.F. 1987. Nutrição mineral de bovinos de corte no Pantanal Mato-grossense. I. Levantamento de macronutrientes na Nhecolândia (parte central). Pesq.Agropec.Bras.22 (9/10):1093-1109. - (17) Pott E.B., Almeida I.L., Brum P.A.R., Comastri Filho J.A., Pott A. \& Dynia J.F. 1989a. Nutrição mineral de bovinos de corte no Pantanal Mato-grossense. II. Micronutrientes na Nhecolândia (parte central). Pesq.Agropec.Bras.24(1):109-126. - (18) Pott E.B., Pott A., Almeida I.L., Brum P.A.R., Comastri Filho J.A. \& Tullio R.R.. 1989b. Nutrição mineral de bovinos de corte no Pantanal Mato-grossense. III. Levantamento de macronutrientes no Baixo Piquiri. Pesq.Agropec.Bras.24(11):1361-1368. - (19) Pott E.B., Brum P.A.R., Pott A., Almeida I.L., Comastri Filho J.A. \& Tullio R.R. 1989c. Nutrição mineral de bovinos de corte no Pantanal Mato-grossense. IV. Levantamento de micronutrientes no Baixo Piquiri. Pesq.Agropec.Bras.24(11):1369- 
1380. - (20) Pott E.B., Brum P.A.R., Almeida I.L., Comastri Filho J.A. \& Pott A. 1989d. Nutrição mineral de bovinos de corte no Pantanal Mato-grossense. V. Levantamento de macronutrientes na sub-região de Aquidauana. Pesq.Agropec.Bras.24(11):1381-1395. - (21) Pott E.B., Comastri Filho J.A., Almeida I.L., Brum P.A.R. \& Pott A. 1989e. Nutrição mineral de bovinos de corte no Pantanal Mato-grossense. VI. Levantamento de micronutrientes na sub-região de Aquidauana. Pesq.Agropec.Bras.24(11):1381-1395. - (22) Riet-Correa F., Bondan E.F., Méndez M.C., Moraes S.S. \& Concepción M.R. 1993. Efeito da suplementação com cobre e doenças associadas à carência de cobre em bovinos no Rio Grande do Sul. Pesq.Vet.Bras.13(3/4):45-49.

lises de amostras de sangue colhidas mensalmente de vacas em lactação, que não recebiam suplementação mineral, nos municípios de Piau, Rio Novo e Rio Preto, Minas Gerais. No segundo ano, vacas do município de Piau receberam suplementação mineral com fósforo, enquanto as do município de Rio Novo receberam suplementação sem esse elemento; o sangue para análise de $\mathrm{P}$ foi colhido bimensalmente. Amostras de capim-gordura (Melinis minutiflora) das pastagens também foram colhidas para análise de P. A suplementação fosfórica teve efeito significativo no nível sérico do elemento nos animais do município de Piau. Com base na baixa produção de leite, no estado geral do rebanho, nos baixos níveis de $P$ nas pastagens e nos animais, foi recomendada a suplementação de fósforo para os animais dos municípios de Piau e Rio Preto.

\section{Magnésio}

Brum et al. (1987a) e Pott et al. (1987, 1989b,d) determinaram que, em relação à sub-região dos Paiaguás, que os níveis de $\mathrm{Mg}$ eram, em todas as épocas estudadas, baixos no solo e nas forrageiras das três unidades geomórficas, e que, portanto, não atenderam às necessidades de vacas em lactação. Por outro lado, tomando como indicativo o osso, os animais só estiveram deficientes em Mg no mês de agosto. Já em relação à sub-região Nhecolândia (parte central), os autores observaram altos níveis de $\mathrm{Mg}$ nos solos de mata e médios a baixos nas demais unidades; as gramíneas satisfariam as necessidades de vacas em lactação apenas em agosto, ainda assim apenas nas unidades "mata" e "lagoa", porém nas demais unidades elas supririam apenas as exigências de vacas secas. Nessa sub-região determinou-se ainda que os níveis de $\mathrm{Mg}$ no soro sanguíneo eram normais em novembro, fevereiro e maio, mas no limiar da normalidade em fevereiro. No que se refere à sub-região Baixo Piquiri não constatouse deficiência de $\mathrm{Mg}$ evidente. No que diz respeito à subregião Aquidauana os autores concluíram que os solos apresentam baixos níveis de $\mathrm{Mg}$ e que no tecido ósseo das vacas em lactação também ocorreram níveis indicativos de deficiência do elemento. O delineamento desse estudo encontrase na parte relativa ao $\mathrm{P}$ e Ca.

Guimarães et al. (1992) estabeleceram que os valores de $\mathrm{Mg}$ na pastagem eram adequados para atender as exigências nutricionais dos bovinos, durante as duas estações do ano. Os níveis de $\mathrm{Mg}$ no plasma e no fígado também foram considerados normais e não apresentaram diferença significativa entre as duas épocas do ano estudadas. Os autores comentam, citando Viana (1976), que deficiências de Mg em bovinos são mais prováveis quando esses animais ingerem forragens com valores abaixo de $0,07 \%$ ou 700 ppm, o que é raro em nosso meio, já que quase não há gramíneas ou concen- trados com menos de $0,1 \%$ desse elemento. $O$ delineamento desse estudo encontra se na parte relativa ao $\mathrm{P}$ e Ca.

Lisbôa et al. (1996) não verificaram anormalidades para os valores de $\mathrm{Mg}$ no soro sangüíneo dos 32 bovinos por eles estudados; as dosagens no tecido ósseo mostraram concentrações normais desse elemento. $O$ delineamento desse estudo consta na parte relativa ao $\mathrm{P}$ e Ca.

Potássio

Pott et al. (1987, 1989b,d) concluíram, em relação à subregião Nhecolândia (parte central), que as concentrações de $\mathrm{K}$ eram baixas nos solos de todas as unidades, exceto na mata, em novembro, porém, nas forrageiras, os níveis do elemento eram adequadas para bovinos em todas as unidades de paisagem, nas três épocas de amostragem. No que diz respeito à sub-região Baixo Piquiri foi concluído que deficiência de $\mathrm{K}$ não é evidente. Em relação à sub-região Aquidauana os solos apresentaram baixos níveis de $\mathrm{K}$. $\mathrm{O}$ delineamento desses estudos encontra-se na parte relativa ao $\mathrm{P}$ e $\mathrm{Ca}$.

Lisbôa et al. (1996) não observaram anormalidades para os valores de K no soro sangüíneo dos 32 animais estudados. $\mathrm{O}$ delineamento desse estudo consta na parte relativa ao $\mathrm{P} \mathrm{e}$ Ca.

\section{Sódio e cloro}

No levantamento das deficiências minerais de bovinos no Pantanal Mato-grossense foi analisada, na sub-região Nhecolândia (parte central), além do solo, de forrageiras, de soro sanguíneo e tecidos animais, também a água de "baías" (lagoas de água doce) e "salinas" (lagoas de água salobre), em relação a $\mathrm{Ca}, \mathrm{Mg}, \mathrm{K}, \mathrm{N}$ e $\mathrm{P}$. Constatou-se que, dentre esses minerais, apenas o sódio, encontrado nas "salinas" (319 ppm - média anual), apresentava importância nutricional para bovinos de corte, pois sua quantidade supria $140 \%$ das necessidades desses animais. Lembram os autores que esse aspecto deve ser levado em consideração por ocasião da formulação de misturas minerais para bovinos que pastejam em áreas onde existem estas lagoas, uma vez que induzem a um menor consumo de sal comum. (Pott et al. 1987)

Lisbôa et al. (1996) não observaram anormalidades para os valores de $\mathrm{Na}$ e $\mathrm{Cl}$ no soro sangüíneo nos 32 bovinos estudados. $\mathrm{O}$ delineamento desse estudo consta na parte relativa ao $\mathrm{P}$ e Ca.

\section{Ferro}

Fichtner et al. (1987) realizaram análises de amostras de solo, forragem e fígado (biopsia) de bovinos em três fazendas representativas do município de Rio Verde, Goiás. Em cada fazenda escolheram-se 10 vacas e 10 bezerros. Os autores verificaram nas forragens de duas fazendas, concentrações de Fe consideradas tóxicas para o gado. Os níveis de 
ferro no fígado eram superiores aos considerados críticos. Vide também cobalto, zinco e manganês.

Brum et al. (1987b) e Pott et al. (1989a,c,e) concluíram, em relação à sub-região dos Paiaguás, que os níveis médios de Fe nas forrageiras atendiam as necessidades de vacas de corte e em lactação, que os níveis médios de Fe nas forrageiras em agosto e fevereiro atingiram valores considerados tóxicos para bovinos de corte e que, porém, os níveis hepáticos de Fe eram normais. Em relação à sub-região Nhecolândia (parte central)) os autores observaram que os elevados teores de ferro no solo, nas gramíneas e no tecido hepático permitem pressupor a ocorrência de toxidez deste mineral para bovinos. Em relação às sub-regiões Baixo Piquiri e Aquidauana verificaram-se também altos níveis de Fe no solo, nas forrageiras e no fígado. $\mathrm{O}$ delineamento desses estudos encontra-se na parte relativa ao $\mathrm{P}$ e $\mathrm{Ca}$.

Na sub-região de Nhecolânia (parte central), as concentrações de microelementos nas águas de "baías" e "salinas" eram muito baixas, sendo mensuráveis apenas os teores de Fe e Mn nas "baías". As concentrações de Fe nas "baías" pode representar cerca de $50 \%$ das necessidades diárias para bovinos de corte. Os autores comentam que os níveis de Fe da água das "baías", principalmente nos meses de seca, quando há concentração dos solutos em decorrência de evaporação, tendem a aumentar a ingestão de Fe pelos bovinos, quando o teor já é alto nas plantas forrageiras. (Pott et al. 1989a)

Guimarães et al. (1992) verificaram elevados níveis de Fe na pastagem, sem variação significativa entre as duas épocas do ano. Os teores de Fe no plasma e no fígado eram adequados durante os períodos chuvoso e seco. Os autores comentam que, como previsto, a deficiência de Fe não era esperada em bovinos criados nessa área, devido a alta concentração de Fe no solo e conseqüentemente nas gramíneas, além da possibilidade dos animais ingerirem alguma quantidade de solo juntamente com a pastagem. $\mathrm{O}$ delineamento desse estudo encontra-se na parte relativa ao $\mathrm{P}$ e Ca.

Moraes et al. (1994), ao investigarem a importância de um possível desequilíbrio de microelementos na dieta dos animais na etiologia da "cara inchada" dos bovinos (CI), dosaram os teores de $\mathrm{Cu}, \mathrm{Mo}, \mathrm{Co}, \mathrm{Zn}, \mathrm{Mn}$ e Fe em 83 amostras de fígado de bovinos, sendo 61 amostras de animais afetados pela $\mathrm{CI}, 17$ de animais sadios e 4 de animais recuperados. Os 17 animais sadios eram também de fazendas CI-positivas e os 4 animais curados tinham sido transferidos para fazendas indenes. Foram coletadas também 48 amostras de pastos onde ocorreu a $\mathrm{CI}$, e 28 de pastos indenes, que foram analisadas para $\mathrm{Cu}, \mathrm{Mo}, \mathrm{S}, \mathrm{Mn}$ e Fe. Os autores descreveram marcada variação nos teores de Fe nas amostras de fígado, o que, de acordo com eles, pode estar ligado a deficiência de $\mathrm{Cu}$ dos animais ou à suplementação mineral utilizada nas diferentes fazendas. Os resultados das amostras de pastagens com incidência de $\mathrm{CI}$ apresentaram-se, em sua maioria, dentro dos requisitos normais; nas pastagens sem incidência de $\mathrm{CI}$, os níveis foram mais elevados. Vide também $\mathrm{Co}, \mathrm{Cu}, \mathrm{Zn}$, Mn e Mo.

Lisbôa et al. (1996) verificaram que os teores hepáticos de Fe apresentaram-se dentro dos limites de normalidade nos
32 bovinos por eles estudados. 0 delineamento desse estudo consta na parte relativa ao $\mathrm{P}$ e Ca.

Moraes (1998), complementando estudos realizados por Tokarnia et al. (1968, 1971), encontraram valores elevados de Fe em numerosas amostras de fígado de bovinos e ovinos, parte destes relacionada com a deficiência de cobre. Vide também Zn e Mn.

Moraes et al. (1999) deram continuidade a seus estudos seguindo a metodologia delineada por Tokarnia et al. (1988), que consistia na obtenção de históricos de doenças possivelmente causadas por deficiências minerais, com observações de campo e exames clínicos de bovinos e ovinos afetados por essas doenças, na realização de necropsias com coleta de material para exames de laboratório e histopatológicos, e em dosagens de Fe, Co, Cu, Zn, Mn e Se nas amostras de fígado coletadas durante a necropsia desses animais. Em relação ao Fe, esses autores verificaram valores elevados em grande parte das amostras de todos os Estados, sobretudo naquelas amostras com baixos valores de cobre. Em algumas ocasiões, sobretudo nos animais afetados pela "doença do peito inchado", doença cardíaca de bovinos no Estado de Santa Catarina, de etiologia ainda não-esclarecida (Tokarnia et al. 1989), e pelo "ronca", doença de bovinos nos Estados do Piauí, Rio de Janeiro e Mato Grosso do Sul, de etiologia também ainda não-esclarecida (Tokarnia \& Döbereiner 1998), os valores de Fe no fígado foram especialmente elevados. Valores baixos de Fe foram constatados em bovinos afetados pela hematúria enzoótica (intoxicação por Pteridium aquilinum). Vide também $\mathrm{Co}, \mathrm{Cu}, \mathrm{Zn}$ e $\mathrm{Mn}$.

\section{Cobre}

Brum et al. (1987b) e Pott et al. (1989a,c,e) concluíram, em relação à sub-região dos Paiaguás, que os solos produziram forrageiras com baixos níveis de $\mathrm{Cu}$ nos quatro períodos, insuficientes às necessidades de vacas de corte em lactação, mas que os níveis hepáticos de $\mathrm{Cu}$ eram normais nas épocas estudadas. Em relação à sub-região Nhecolândia (parte central) concluíram que, apesar das concentrações normais de $\mathrm{Cu}$ encontradas no fígado dos bovinos, as baixas concentrações existentes nos solos e nas gramíneas, aliadas às elevadas concentrações de Fe, permitem sugerir a conveniência da suplementação de $\mathrm{Cu}$ para bovinos nesta sub-região. Em relação à sub-região Baixo Piquiri, verificaram que não há deficiência de Cu no solo, que nas forrageiras os níveis de $\mathrm{Cu}$ são baixos em algumas espécies, e que há possibilidade da ocorrência de deficiência de $\mathrm{Cu}$, especialmente no início do período chuvoso, apesar de os teores médios de $\mathrm{Cu}$ no fígado nas quatro épocas estarem dentro da faixa normal. Em relação à sub-região Aquidauana os autores concluíram, que, aparentemente, não há deficiência de $\mathrm{Cu}$ no solo, que as forrageiras em grande parte são deficientes em $\mathrm{Cu}$, e que não houve ocorrência de teores hepáticos que caracterizassem deficiência de $\mathrm{Cu}$ nos bovinos. $\mathrm{O}$ delineamento desses estudos encontra-se na parte relativa ao $\mathrm{P}$ e Ca.

Sousa et al. (1989), no levantamento das deficiências minerais em bovinos no nordeste de Roraima, verificaram que os níveis médios de Cu no fígado variaram de 120 a 271 ppm 
e os de Mo de 1,58 a 3,33 ppm, sendo considerados adequados para bovinos. Os teores de $\mathrm{Cu}$ e Mo nas forrageiras variaram de 1,5 a $3,6 \mathrm{ppm}$ e de 0,51 a $0,54 \mathrm{ppm}$, respectivamente; as concentrações de $\mathrm{Cu}$ nas forrageiras estavam abaixo do mínimo recomendado para bovinos, enquanto o Mo apresentou níveis adequados. Uma possível explicação para a manutenção dos níveis de Cu no fígado dentro dos limites normais, pode, conforme lembram os autores, estar relacionada com os níveis relativamente baixos de Mo encontrados nas forrageiras. $\mathrm{O}$ delineamento dos estudos de Sousa et al. (1989) encontra-se em Tokarnia et al. (1988).

Bondan et al. (1991) determinaram os níveis de cobre em 365 amostras de fígado de bovinos, provenientes de animais da área de influência do Laboratório Regional de Diagnóstico, da Universidade Federal de Pelotas, Rio Grande do Sul. Concentrações de $\mathrm{Cu}$ iguais ou inferiores a 25 ppm (base seca) foram encontradas em 31,34 e 31,16\% dos fígados de vacas e novilhos de abate, respectivamente, e em $36,36 \%$ de materiais de necropsia, evidenciando uma marcada depleção dos níveis hepáticos do elemento. De um total de nove bovinos com níveis hepáticos de $\mathrm{Cu}$ inferiores a 5 ppm (base seca), oito apresentaram morte súbita.

Guimarães et al. (1992) concluíram que os baixos teores de Cu no plasma das novilhas sugerem uma deficiência marginal nesse microelemento. $O$ delineamento desse estudo encontra-se na parte relativa ao $\mathrm{P}$ e Ca.

Riet-Correa et al. (1993) relataram com detalhes a ocorrência das mortes súbitas mencionadas por Bondan et al. (1991) e, adicionalmente, a ocorrência da hipomielinogênese congênita em bovinos. Todos os casos de morte súbita e de ataxia neonatal, assim como a resposta positiva à suplementação com $\mathrm{Cu}$ realizada experimentalmente, foram constatados em estabelecimentos nas margens da Lagoa dos Patos e da Lagoa Mirim, nas regiões do Rio Grande do Sul denominadas de Litoral e Encosta do Sudeste, nas quais Bondan et al. (1991) encontraram níveis hepáticos de cobre significativamente menores do que em outras regiões do sul do Estado.

Moraes et al. (1994) verificaram, em relação ao $\mathrm{Cu}$, que os bovinos da região de Rondonópolis (mun. Rondonópolis e Jaciara), na sua maioria, são carentes (deficientes e subdeficientes) neste elemento, independentemente de serem afetados pela $\mathrm{CI}$ ou não. Por outro lado, amostras de fígado de bovinos com $\mathrm{Cl}$ coletadas em fazendas de outras regiões, positivas para a doença, revelaram, na sua maioria, teores normais ou elevados de Cu. Disto pode-se deduzir que a $\mathrm{CI}$ não está relacionada com os baixos níveis de $\mathrm{Cu}$ nos animais, mas sim que esses valores indicam que há uma acentuada deficiência deste microelemento na região de Rondonópolis. As análises das pastagens revelaram níveis de $\mathrm{Cu}$ adequados, tanto nas pastagens positivas para $\mathrm{CI}$, como nas negativas, porém elevados de Mo e principalmente de $S$. A deficiência de $\mathrm{Cu}$ nos animais provavelmente estaria relacionada à interação Cu-Mo-S. O delineamento desse estudo encontrase na parte relativa ao $\mathrm{Fe}$.

Lisbôa et al. (1996) determinaram que os teores hepáticos de $\mathrm{Cu}$ apresentaram-se dentro dos limites de normalidade. $\mathrm{O}$ delineamento desse estudo consta na parte relativa ao P e Ca.
Moraes et al. (1999) diagnosticaram a ocorrência de deficiência de Cu no município de Barra do Bugres (MT), em dois bovinos afetados pelo "ronca", doença de etiologia ainda nãoesclarecida (Tokarnia \& Döbereiner 1998), examinados no município de Aquidauana (MS), e ainda nos municípios de Parintins (AM), Carolina (MA), no nordeste do Estado de Minas Gerais, na parte sul do Estado do Rio de Janeiro, e nos municípios de Itaquí e Uruguaiana (RS). O delineamento desses estudos encontra-se na parte relativa ao Fe.

Intoxicação por cobre. Riet-Correa et al. (1989) descreveram a intoxicação crônica por $\mathrm{Cu}$ em ovinos em quatro estabelecimentos no Rio Grande do Sul. Os sinais clínicos consistiram em anorexia, depressão, icterícia, hemoglobinúria, fezes líquidas, fétidas e escuras, e morte em 1 a 4 dias. À necropsia foram constatadas icterícia generalizada, presença de líquido seroso nas cavidades, fígado friável de cor amarelada ou laranja, urina de cor café ou vermelho- escura, rins de coloração marrom-escura, edemaciados e de consistência diminuída. Os exames histológicos revelaram no fígado principalmente vacuolização dos hepatócitos, as vezes com pigmento de aspecto granular de cor amarelo-clara, células de Kupffer repletas de pigmento marrom-amarelado, nos canalículos biliares retenção de bile, nos rins presença de cilindros granulares vermelhos ou hialinos, vacuolização das células epiteliais, às vezes com pigmento amarelo-claro nos vacúolos. Os níveis de $\mathrm{Cu}$ em fígados e rins de cinco ovinos afetados variaram de 489 a 1760 ppm e 60 a 470 ppm da matéria seca, respectivamente (níveis de Cu superiores a 500 ppm no fígado e de $100 \mathrm{ppm}$ nos rins indicam a ocorrência da intoxicação de acordo com Pope 1971, citado pelos autores). Os níveis de $\mathrm{Cu}$ de 28 rações, provenientes de 8 diferentes fabricantes, em 11 apresentaram entre 18 e 20 ppm e em 17 mais de 20 ppm de $\mathrm{Cu}$ (concentrados com mais de 20 ppm podem causar intoxicação crônica primária de acordo com Blood et al. 1979, citados pelos autores). Concluíram que a intoxicação por Cu ocorre devido aos altos níveis deste elemento nas rações para ovinos utilizadas no Rio Grande do Sul. Recomendam não adicionar $\mathrm{Cu}$ na formulação da ração para essa espécie.

Pilati et al. (1990) descreveram dois surtos de intoxicação crônica por cobre em ovinos no Rio Grande do Sul, com morte de pelo menos 21 animais. Os sinais clínicos incluíram depressão, anorexia, icterícia e hemoglobinúria; a evolução era de 4 a 6 dias. As lesões mais constantes vistas na necropsia foram icterícia, fígado amarelo ou alaranjado, rins "escuros" e tumefeitos. Os exames histológicos revelaram no fígado necrose centrolobular, retenção biliar intracitoplasmática e intracanalicular, proliferação de tecido conjuntivo periportal, vacuolização de hepatócitos, alguns contendo fragmentos de material amarelo-brilhante, moderada hiperplasia de ductos biliares e fibroplasia portal, apoptose e pleomorfismo celular com megalocitose, células de Kupffer carregadas de pigmento amarelo, no rim vacuolização de células epiteliais dos túbulos uriníferos contendo material eosinofílico em seus lúmens e presença de pigmento biliar no interior de algumas células epiteliais. Os valores de $\mathrm{Cu}$ no fígado, em quatro de 
cinco ovinos, oscilaram entre 1212 e 2071 ppm e no rim, também em quatro de cinco ovinos, entre 124 e 159 ppm.

Ribeiro et al. (1995) diagnosticaram, também no Rio Grande do Sul, a intoxicação crônica por Cu em um grupo de 120 ovelhas que foram colocadas a pastorear em pomar de macieiras, o qual foi aspergido com sulfato de cobre 4 semanas após a introdução dos animais. Um mês após a aspersão apareceram ovinos com tristeza, andar cambaleante, icterícia e hemoglobinúria, dos quais 21 morreram. Os achados de necropsia consistiram em icterícia generalizada e rins aumentados de volume; a bexiga continha urina de cor achocolatada. Os exames histológicos revelaram, no fígado, hepatócitos com vacúolos, necrose hepática predominantemente na região periacinar, fibroplasia periportal e pigmento de coloração acastanhada no interior das células de Kupffer, no rim degeneração e necrose do epitélio tubular e presença de cilindros granulares de coloração vermelho-escura no interior dos túbulos renais. A coloração pelo ácido rubeânico demonstrou a presença de grânulos positivos para Cu no interior das células de Kupffer e de hepatócitos necróticos. Análises revelaram 60 ppm de Cu em amostra da pastagem e 1313 e 300 ppm de $\mathrm{Cu}$, respectivamente, em amostras de fígado e rins.

Ribeiro et al. (1985) diagnosticaram no Rio Grande do Sul, intoxicação por $\mathrm{Cu}$ em cinco ovinos submetidos por um período longo a dieta de concentrados. Nos quatro animais necropsiados verificaram principalmente icterícia generalizada e bexiga contendo urina "escura". A coloração pelo método do ácido rubeânico revelou presença de grânulos de $\mathrm{Cu}$ no interior dos hepatócitos e das células de Kupffer. Análises químicas revelaram valores de 976 a 2438 ppm de Cu no fígado e de 232 a 1467 ppm nos rins. As quatro rações examinadas revelaram níveis entre 15 e 65 ppm de Cu.

\section{Cobalto}

Fichtner et al. (1987) verificaram que em Rio Verde, Goiás, as amostras de solo, em média, não apresentaram deficiência de cobalto, entretanto, a maioria das amostras de forragens e de fígado de bovinos mostraram valores tidos como deficientes. $\mathrm{O}$ delineamento desse estudo encontra-se na parte relativa ao Fe.

No levantamento das deficiências minerais de bovinos no Pantanal Mato-grossense foi concluído que na sub-região Nhecolândia (parte central), única área onde foram realizadas análises para Co em amostras de fígado (só foram coletadas no mês de novembro), os teores desse mineral eram bastante elevados $(1,1 \pm 0,3 \mathrm{ppm})$; aparentemente não há ocorrência de deficiência de cobalto nesta sub-região ( Pott et al. 1989 a).

Moraes et al. (1994), ao investigarem a importância de um possível desequilíbrio de microelementos na dieta animal na etiologia da "cara inchada" dos bovinos $(\mathrm{CI})$, verificaram teores de Co adequados em todos os animais sadios ou afetados pela $\mathrm{CI}$ em fazendas $\mathrm{CI}$-positivas na região de Rondonópolis, e de quase todos os animais com CI e nos sadios de fazendas $\mathrm{Cl}$-positivas de outras regiões. $\mathrm{O}$ delineamento desse estudo encontra-se na parte do Fe.

Lisbôa et al. (1996) São Paulo, determinaram que os teo- res hepáticos de Co nos 32 bovinos estudados por eles estavam dentro dos limites de normalidade. $O$ delineamento desse estudo consta na parte relativa ao $\mathrm{P}$ e Ca.

Moraes et al. (1999) diagnosticaram a ocorrência de deficiência de Co nos municípios de Barra do Bugres e Diamantina (MT), no município de Boa Vista (RR), nos municípios de Manaus e Itacoatiara (AM), no nordeste do Estado do Minas Gerais, nos municípios de Luiz Antonio (SP) e de Seropédica (RJ). Ainda foram verificados baixos teores hepáticos de cobalto no município de Urubici no leste de Santa Catarina, onde ocorre, em bovinos, a "doença do peito inchado", de etiologia ainda nãoesclarecida (Tokarnia et al. 1989). O delineamento desses estudos encontra-se na parte relativa ao Fe.

\section{Zinco}

Penna et al. (1983) realizaram análises químicas para Zn em forrageiras e em amostras de fígado de bovinos obtidas por biopsia, nos períodos chuvoso e seco, no município de Ipirá, Bahia. Observaram baixos valores de $\mathrm{Zn}$ na maioria das amostras de forrageiras e de fígados, tanto nos bovinos adultos, quanto nos jovens, independentemente da época do ano.

Fichtner et al. (1987) verificaram que a maioria das amostras de solo foram deficientes em $\mathrm{Zn}$, mas as amostras de forragem e fígado tiveram valores dentro de limites considerados normais. $O$ delineamento desse estudo encontra-se na parte relativa ao Fe.

Brum et al.(1987b) e Pott et al.(1989a,c,e) concluíram, em relação à sub-região dos Paiaguás, que os solos produziram, nos quatro períodos, forrageiras com níveis de $\mathrm{Zn}$ considerados insuficientes às necessidades de vacas de corte em lactação, que os animais estudados apresentaram níveis de $\mathrm{Zn}$ considerados deficientes em agosto, fevereiro e maio, e que só em novembro os níveis médios de $\mathrm{Zn}$ no fígado eram adequados. Em relação à sub-região Nhecolândia (parte central) os autores determinaram que, embora os níveis hepáticos de $\mathrm{Zn}$ geralmente fossem normais, deve-se considerar a conveniência de suplementação de $\mathrm{Zn}$ nesta sub-região, em face: 1) da ocorrência de níveis marginais em algumas vacas, em todas as épocas e sobretudo em novembro, a partir de quando geralmente acontece o pico de crescimento/ganho de peso dos bovinos na região, 2) da ocorrência de níveis baixos de $\mathrm{Zn}$ nos solos e nas gramíneas, e 3) da ocorrência de elevados teores de Fe nos solos, nas gramíneas e no tecido hepático. Em relação à sub-região Baixo Piquiri os autores verificaram que os níveis de $\mathrm{Zn}$ nos solos são muito variáveis, que nas forrageiras os teores de $Z n$ são baixos, e que há possibilidade de ocorrer deficiência de Zn nos bovinos, sobretudo no período seco, quando os valores hepáticos forem baixos. Em relação à sub-região Aquidauana concluíram que os solos apresentam teores muito variáveis de $\mathrm{Zn}$, que as forrageiras são deficientes em $\mathrm{Zn}$, que não houve ocorrência de teores hepáticos que caracterizassem deficiência de $\mathrm{Zn}$ nos bovinos, mas que os baixos teores de $\mathrm{Zn}$ nas forrageiras, os altos teores de Fe nas forrageiras e no fígado e o alto percentual de vacas com teor hepático de Zn no limiar da normalidade permitem sugerir a conveniência da suplemen- 
tação de $\mathrm{Zn}$ nessa sub-região. $\mathrm{O}$ delineamento desses estudos encontra-se na parte relativa ao $\mathrm{P}$ e $\mathrm{Ca}$.

Costa et al. (1992) em seu estudo experimental em novilhos de engorda em Diamantina, Mato Grosso, concluíram que as análises de forrageiras indicam deficiência de $\mathrm{Zn}$. O delineamento desse estudo encontra-se na parte relativa a $\mathrm{P}$ e Ca.

Guimarães et al. (1992) encontraram no fígado dos bovinos valores de Zn que sugerem uma deficiência marginal desse microelemento. $O$ delineamento desse estudo encontra-se na parte relativa ao $\mathrm{P} \mathrm{e} \mathrm{Ca}$.

Moraes et al. (1994) verificaram que os teores de $\mathrm{Zn}$ no fígado dos bovinos com $\mathrm{CI}$, tanto nos da região de Rondonópolis como nos de outros regiões, eram mais elevados do que naqueles que não apresentavam a doença ou tinham sido curados; esses autores chegaram a conclusão que os elevados valores possivelmente sejam o resultado de uma maior concentração de metalotionina no fígado, induzida pelo próprio processo patológico no animal. Os valores obtidos nas amostras de pastagens, tanto nas de fazendas com $\mathrm{CI}$ como nas sem incidência de $\mathrm{Cl}$, sugerem, de acordo com os autores, uma tendência à deficiência de $\mathrm{Zn}$ em alguns pastos. O delineamento desse estudo encontra-se na parte relativa ao Fe.

Lisbôa et al. (1996) verificaram que os teores hepáticos de $\mathrm{Zn}$ dos 32 bovinos por eles estudados estavam dentro dos limites de normalidade. $O$ delineamento desse estudo consta na parte relativa ao $\mathrm{P}$ e $\mathrm{Ca}$.

Moraes (1998) verificou, na maioria das regiões abrangidas no seu estudo, que os valores de $\mathrm{Zn}$ só esporadicamente estiveram abaixo do nível considerado normal. Apenas nos Estados do Ceará e do Piauí, um maior número de amostras apresentou baixos teores para este mineral, sugerindo a ocorrência de deficiência de $\mathrm{Zn}$, mas sob forma sub-clínica, pois os históricos e estudos clínico-patológicos não indicavam a ocorrência desta deficiência. $O$ delineamento desse estudo consta na parte relativa ao Fe.

Moraes et al. (1999) verificaram valores de $\mathrm{Zn}$ indicativos de deficiência só no município de Seropédica (RJ). $O$ delineamento desses estudos encontra-se na parte relativa ao Fe.

\section{Manganês}

Fichtner et al. (1987) não encontraram deficiência de Mn em amostras de solo, nem em amostras de forragem. $\mathrm{O}$ delineamento desse estudo encontra-se na parte relativa ao $\mathrm{Fe}$.

Brum et al. (1987b) e Pott et al. (1989a,c,e) concluíram, em relação à sub-região dos Paiaguás, que os níveis médios de $\mathrm{Mn}$ nas forrageiras atenderam às necessidades de vacas de corte em lactação e que os níveis hepáticos de Mn eram normais nas épocas estudadas. Em relação à sub-região Nhecolândia (parte central), os autores afirmaram que os elevados teores $\mathrm{Mn}$ (e Fe) nos solos, nas gramíneas e no tecido hepático permitem pressupor a ocorrência de toxidez destes dois minerais para bovinos, pelo menos no final da época chuvosa. Em relação às sub-regiões Baixo Piquiri e Aquidauana eles também encontraram elevados níveis de Mn no solo, nas forrageiras e no figado dos bovinos. $\mathrm{O}$ delineamento desses estudos encontra-se na parte relativa ao $\mathrm{P}$ e Ca.
Moraes et al. (1994) encontraram teores de Mn considerados normais na maioria das amostras de fígado. A maioria dos valores de Mn encontrados nas amostras de pasto, estava acima do requisito máximo para bovinos de corte, com ou sem incidência de $\mathrm{CI}$. $\mathrm{O}$ delineamento desse estudo encontra-se na parte do $\mathrm{Fe}$.

Lisbôa et al. (1996) observaram teores hepáticos de Mn dentro da normalidade nos 32 bovinos por eles estudados. $\mathrm{O}$ delineamento desse estudo consta na parte relativa ao $\mathrm{P} \mathrm{e} \mathrm{Ca}$.

Moraes (1998) verificou, na maioria das regiões estudadas, valores de Mn só esporadicamente abaixo do nível considerado normal. Somente nos Estados do Rio de Janeiro (Sul), do Espírito Santo (Norte), do Ceará (Serra da Ibiapaba) e do Amapá havia uma maior incidência de baixos valores de Mn, fato que sugere deficiência subclínica de Mn, pois os históricos e estudos clínico-patológicos não indicavam a ocorrência desta deficiência. O delineamento desse estudo consta na parte relativa ao $\mathrm{Fe}$.

Moraes et al. (1999) observaram baixos valores de Mn no nordeste de Minas Gerais, e em bovinos afetados pela "doença do peito inchado", doença de etiologia ainda não esclarecida que ocorre em bovinos no Estado de Santa Catarina (Tokarnia et al. 1989). Por outro lado, esses autores encontraram altos valores de $\mathrm{Mn}$ em bovinos submetidos a experimentação com Baccharis coridifolia, nos municípios de Cacequí, Itaquí e Uruguaiana (RS). O delineamento desse estudo encontra-se na parte relativa ao $\mathrm{Fe}$.

\section{Molibdênio}

No levantamento das deficiências minerais de bovinos no Pantanal Mato-grossense foi concluído, em relação à sub-região Nhecolândia (parte central), única sub-região onde foram realizadas análises de Mo, que os valores de Mo no solo e nas amostras de fígado estão, respectivamente, no limite inferior dos considerados normais e dentro da faixa normal (Pott et al. 1989a).

Moraes et al. (1994) verificaram que os teores de Mo nas amostras de fígado estavam, na sua maioria, normais, ou, em menor escala, elevados, com grande variação tanto nos bovinos com $\mathrm{Cl}$, quanto nos sadios. $\mathrm{O}$ delineamento desse estudo encontra-se na parte do $\mathrm{Cu}$.

Selênio (com inclusão dos poucos dados sobre esse elemento que já constavam em revisão anterior - Tokarnia et al. 1988)

A primeira ocorrência da miopatia nutricional ("doença do músculo branco") foi registrada no Rio Grande do Sul (Barros et al. 1988). Numa propriedade de 140 bezerros de aproximadamente um ano de idade que eram mantidos em uma pastagem de azevém, 40 animais morreram. A evolução da doença foi de 1 a 3 dias e os sinais clínicos incluíram rigidez dos músculos dos membros e dificuldade de locomoção. À necropsia, realizada em um bezerro, havia lesões nos músculos esqueléticos e, em menor grau, no miocárdio. As lesões microscópicas eram sobretudo degenerativas, havendo acentuada calcificação de fibras. Após tratamento com vitamina $\mathrm{E}$ e selênio não houve aparecimento de novos casos e alguns 
animais levemente afetados recuperaram-se. Em outra propriedade foi observado caso isolado de miopatia em uma bezerra, que morreu subitamente sem apresentar sinais clínicos prévios. Na necropsia foram vistas lesões semelhantes às observadas nos animais do surto acima descrito, porém mais pronunciadas no coração. As lesões microscópicas também eram semelhantes, mas as do miocárdio incluíam marcadas alterações proliferativas acompanhadas por infiltrado de macrófagos e outras células mononucleares.

Anteriormente, Mello et al. (1973) haviam relatado a ocorrência da hepatose dietética em suínos. A doença, que causou a morte de 29 porcos no município de Patos de Minas (Minas Gerais), era caracterizada por morte súbita; à necropsia havia edemas subcutâneo e pulmonar, hialinização da parede arteriolar e degeneração dos músculos esqueléticos e do coração. Os animais tinham sido alimentados com milho e sorgo pobres em Se $(0,07$ e $0,03 \mathrm{ppm}$, respectivamente).

Foram realizados alguns levantamentos com determinação dos níveis de Se em amostras de soro sanguíneo de bovinos (Lucci et al. 1984a), em amostras de alimentos fornecidos ao gado (Lucci et al. 1984b) e em amostras de fígado de bovinos (Moraes 1986, Moraes et al. 1999).

Assim, Lucci et al. (1984a) determinaram para as duas estações do ano (de chuvas e de estiagem) os níveis de Se em 1.973 amostras de soro sanguíneo coletadas de vacas de 80 rebanhos leiteiros, de 12 diferentes regiões, em que dividiram o Estado de São Paulo. Em $78 \%$ das vacas havia níveis baixos de Se (0,04 ppm ou menos). Não ocorreram diferenças significativas entre os períodos de chuvas e de estiagem. Só as vacas da região do Vale do Ribeira apresentaram níveis de Se considerados adequados. Baseados em informações subjetivas, os autores ainda informaram que parece ter ocorrido grande incidência de casos de retenção de placenta em quase todas as fazendas visitadas.

Lucci et al. (1984b) analisaram os níveis de Se em 416 amostras de alimentos fornecidos ao gado nos 80 rebanhos localizados nas mesmas regiões do Estado de São Paulo. Em cada fazenda colheram amostras das misturas de concentrado e dos pastos, silagens e fenos. Os resultados indicaram deficiência de Se nas gramíneas, que se acentuou no período de estiagem. $\mathrm{O}$ milho, quer como planta inteira, quer na forma de grão, mostrou-se pobre em Se. $\mathrm{O}$ farelo de trigo mostrou-se rico neste mineral.

Moraes (1986) verificou em Mato Grosso que, de 12 bovinos afetados por "cara inchada" (CI), 4 apresentaram baixos valores de Se nas amostras de fígado analisadas; de outras 5 amostras de fígado de bovinos sadios, procedentes de fazendas Cl-positivas, uma, procedente de Rondonópolis, tinha valor baixo em Se. Adicionalmente, Moraes et al. (1999) observaram de um total de outros 15 bovinos não-relacionados com o estudo da $\mathrm{CI}$, procedentes de Mato Grosso, baixos valores de Se em mais duas amostras de fígado, de bovinos originários de Poconé e Rondonópolis. Resumindo, ao todo foram obtidos 7 valores baixos em Se em 32 amostras analisadas em Mato Grosso. Em Mato Grosso do Sul, Moraes (1986) encontrou valores normais nas amostras de fígado de 3 bovinos com $\mathrm{Cl}$ e um valor indicando deficiência em amostra de um bovino sadio de fazenda
Cl-positiva. Moraes et al. (1999) constataram, de um total de outros 16 amostras de fígado não-relacionadas com o estudo da $\mathrm{CI}$, procedentes de Mato Grosso do Sul, baixos valores de Se em 7 delas. Quatro dessas amostras eram provenientes de bovinos intoxicados por Solanum malacoxylon (calcinose) em Corumbá, duas outras oriundas do município de Aquidauana (um bovino afetado pela calcinose, outro pelo "ronca") e a sétima procedia de um bovino afetado por botulismo, em Amambaí. Resumindo, ao todo foram obtidos 8 valores baixos em Se em 20 amostras analisadas em Mato Grosso do Sul. Valores elevados de Se foram verificados no município de Boa Vista, Roraima. Um delineamento dos estudos de Moraes et al. (1999) encontra-se na parte relativa ao Fe.

Ainda foram realizados diversos trabalhos experimentais sobre o efeito da suplementação do Se ou Se combinado com vitamina $E$, na retenção da placenta, na gestação e fertilidade de vacas e no desenvolvimento e crescimento de bovinos (bezerros, novilhos e novilhas).

Assim, em relação a retenção de placenta, Lucci et al. (1985) realizaram um estudo em 120 vacas de criações situadas em quatro municípios do Estado de São Paulo (Descalvado, São João da Boa Vista, Itirapina e São Carlos). Os autores concluíram que a suplementação de Se na forma inorgânica foi mais eficiente do que a suplementação na forma orgânica pelo farelo de trigo, mas que a administração de selenito de sódio diminuiu a incidência de retenção de placenta em apenas duas das quatro propriedades estudadas. Os dados contidos nesse trabalho foram fornecidos com maiores detalhes, separadamente, para cada um dos municípios acima mencionados, isto é, de Descalvado (Lucci et al. 1984c), São João da Boa Vista (Lucci et al. 1986a), São Carlos (Lucci et al. 1986b) e Itirapina (Lucci et al. 1987).

Rosa et al.(1985a), em experimentos realizados em vacas da raça holandesa, no município de Descalvado, São Paulo, concluíram que o Se associado ou não à vitamina $E$, não influenciou a incidência de retenção de placenta.

Santiago (1986a) observou uma diminuição dos casos de retenção de placenta, além de outras manifestações favoráveis enumeradas no ítem seguinte, em vacas da raça charolesa, que receberam com 240/260 dias em gestação $1 \mathrm{ml} / 100 \mathrm{~kg}$ de selênio-tocoferol,

Vasconcelos et al. (1989) fizeram investigações durante os anos de 1984 e 1985 para avaliar os efeitos da aplicação de Se, de vitamina $E$, e de Se associado à vitamina $E$ na incidência da retenção de placenta, em rebanhos leiteiros em Barbacena e Passos (Minas Gerais), nos quais os níveis de Se no soro sanguíneo estiveram levemente deficientes. Chegaram à conclusão que, em Barbacena, a administração de Se foi eficaz, enquanto que em Passos este efeito não se fez sentir.

Em relação a gestação e fertilidade em vacas, Zanetti et al. (1984) suplementaram, no município de Batatais, São Paulo, vacas da raça holandesa vermelho e branca, em final de gestação (últimos 2 meses) com $2 \mathrm{mg}$ ou $4 \mathrm{mg}$ de Se/vaca/dia, através de selenito de sódio. Verificaram, apesar de não haver diferenças estatísticas, que os animais suplementados com as doses maiores foram inseminados mais cedo e necessitaram de um menor número de inseminações por concepção. 
Santiago (1986a) verificou, no Rio Grande do Sul, uma diminuição na duração média da gestação, dos partos auxiliados e da duração do puerpério clínico, além da diminuição de casos de retenção de placenta, em vacas da raça charolesa com 240/260 dias em gestação, que foram tratadas com $1 \mathrm{ml} /$ $100 \mathrm{~kg}$ de selênio-tocoferol; o grupo tratado também teve bezerros mais pesados ao nascer e mostrou mais precocemente o primeiro cio pós-parto.

Santiago (1986b) observou ainda, no Rio Grande do Sul, um aumento no índice de fecundação, diminuição do número de inseminações por concepção e do intervalo entre parto e fecundação, em dois grupos de vacas da raça charolesa, que foram tratadas, respectivamente, 30 dias pré-parto, 30 dias pré-parto e 60 dias pós-parto, com $1 \mathrm{ml} / 100 \mathrm{~kg}$ de selêniotocoferol,

Em relação ao desenvolvimento e crescimento de bovinos, Rosa et al. (1985b) ao estudarem o efeito da injeção de Se, associado ou não à vitamina $\mathrm{E}$, sobre o crescimento de novilhas e novilhos da raça Nelore mantidos em regime de pasto, na região de Jaboticabal, São Paulo, no período entre dezembro e abril, concluíram que os ganhos de peso não diferiram significativamente entre os diferentes tratamentos, indicando que o selênio ou a sua associação com a vitamina E não teve influência sobre o parâmetro analisado.

Por sua vez, Santiago (1985), com o propósito de determinar, no Rio Grande do Sul, a influência de selênio-tocoferol no crescimento de bezerros de corte da raça Charolesa, com idade de 7 a 11 meses, mantidos em confinamento ou no pasto, verificou que o tratamento com $1 \mathrm{ml} / 100 \mathrm{~kg}$ de selêniotocoferol proporcionou um maior ganho de peso nos animais tratados.

Em outro experimento, também realizado no Rio Grande do Sul, Santiago (1986c) verificou em bezerros da raça charolesa, nascidos de mães tratadas com a emulsão de selênio-tocoferol durante a gestação, uma diminuição do stress do desmame e maior ganho de peso, quando receberam o mesmo produto na dose de $1 \mathrm{ml} / 100 \mathrm{~kg}$.

\section{DISCUSSÃO E CONCLUSÕES}

Confirmou-se o observado anteriormente por ocasião das duas revisões realizadas em 1976 e 1988, ampliando-se e acrescentando-se mais alguns dados a estes conhecimentos. Havia sido verificado que a deficiência de fósforo era a deficiência mineral mais importante em bovinos no Brasil. Depois da deficiência de fósforo, as de cobre e cobalto eram as deficiências minerais mais comuns. Ainda tinham sido diagnosticadas as deficiências de zinco, manganês, iodo e selênio. Tinha sido confirmada através da experimentação em bovinos em uma fazenda em Mato Grosso do Sul a deficiência de sódio, que se suspeita ser de ocorrência muito comum no Brasil. Neste último período poucos trabalhos foram realizados em relação aos macroelementos. Destacam-se os estudos sobre a ocorrência da deficiência de fósforo, em Minas Gerais, diagnosticada através da experimentação complementada por análises de sangue e de amostras de pastagem (Dayrell \& Resz 1984), no Estado de Mato Grosso diagnosticada pela experi- mentação, complementada por análises das cinzas de ossos e de amostras de forrageiras (Costa et al. 1992), e no Pantanal Mato-grossense, diagnosticada pela análise de amostras de solo, pastagem, sangue e tecido ósseo (Brum et al. 1987a, Pott et al. 1987, 1989b,d,).

Baixos valores de ferro em amostras de fígado foram constatados em bovinos afetados pela hematúria enzoótica (Moraes et al. 1999), o que é compreensível, já que os animais apresentam marcada anemia devido a perda constante de sangue.

Por outro lado, valores elevados de ferro, que os autores presumem toxicos para bovinos, foram verificados no Estado de Goiás no município de Rio Verde (Fichtner et al. 1987) e no Pantanal Mato-grossense (Brum et al. 1987b, Pott et al. 1989a,c,e). Valores elevados de ferro ainda foram verificados em grande parte das amostras de fígado em todos os Estados do Brasil, sobretudo naquelas amostras com baixos valores de cobre (Moraes 1998, Moraes et al. 1999). Valores de ferro especialmente elevados foram encontrados nas amostras de fígado dos bovinos afetados pela doença vulgarmente chamada de "ronca" e pela "doença do peito inchado" (Tokarnia \& Döbereiner 1998, Tokarnia et al. 1989). No que se refere ao "ronca", deve se considerar a hipótese de que os níveis hepáticos de ferro estão muito elevados em decorrência da sua não-utilização em função da deficiência de cobre. No caso da "doença do peito inchado", as alterações nos níveis de ferro possivelmente sejam apenas o reflexo do acúmulo de sangue no fígado, uma vez que essa enfermidade é caracterizada por insuficiência cardíaca crônica que cursa, sempre, com acentuada congestão hepática.

Em relação aos microelementos, as deficiências de cobre e cobalto foram confirmadas como as mais frequentes. A deficiência de cobre foi diagnosticada adicionalmente, com base de valores baixos deste elemento no fígado, no Estado do Rio Grande do Sul, na região de Pelotas e municípios vizinhos (Bondan et al. 1991, Riet-Correa et al. 1993). Deve ser destacada a notificação apresentada por estes autores sobre a ocorrência de "mortes súbitas" e da hipomielinogênese congênita em bovinos oriundos de propriedades situadas nas margens da Lagoa dos Patos e da Lagoa Mirim. Nesta região foi verificada uma resposta positiva à suplementação com cobre. Deficiência de cobre ainda foi diagnosticada, com base principalmente nos baixos valores de cobre em amostras de fígado, no Estado de Mato Grosso na região de Rondonópolis (Moraes et al. 1994), e no município de Barra do Bugres, no Estado de Amazonas no município de Parintins, no Estado do Maranhão no município de Carolina, no nordeste do Estado de Minas Gerais, na parte sul do Estado do Rio de Janeiro e no Rio Grande do Sul nos municípios de Itaquí e Uruguaiana (Moraes et al. 1999). Deve ser mencionado à parte o estudo sobre o "ronca", doença crônica de bovinos cuja etiologia ainda não pode ser estabelecida, em que os valores hepáticos para cobre são muito baixos (Tokarnia \& Döbereiner 1998).

Por outro lado, a intoxicação por cobre foi diagnosticada por diversas vezes, sempre em ovinos, e sempre no Estado do Rio Grande do Sul (Ribeiro et al. 1985, 1995, Pilati et al. 1990 e Riet-Correa et al. 1989). 
A deficiência de Co foi novamente constatada, com base nos baixos níveis do elemento em amostras de fígado e de forrageiras, no Estado de Goiás no município de Rio Verde (Fichtner et al. 1987), e ainda, com base nos baixos níveis do elemento em amostras de fígado associados à obtenção de dados sobre quadros clínico-patológicos sugestivos, no Estado de Mato Grosso nos municípios de Barra do Bugres e Diamantina, no Estado de Roraima no município de Boa Vista, no Estado de Amazonas nos municípios de Manaus e Itacoatiara, no nordeste do Estado de Minas Gerais, no Estado de São Paulo no município de Luiz Antonio e no Estado do Rio de Janeiro no município de Seropédica. Foram ainda verificados baixos teores hepáticos de cobalto no município de Uribici no leste de Santa Catarina, onde ocorre a "doença do peito inchado"(Moraes et al. 1999).

A deficiência de zinco foi verificada com bastante frequência no período abrangido por esta revisão. Assim, com base de níveis baixos deste elemento em amostras de fígado e de forrageiras, no Estado da Bahia no município de Ipirá (Penna et al. 1983), com base de análises de amostras de fígado, forrageiras e solo, no Pantanal Mato-grossense (Brum et al. 1987b, Pott et al. 1989a,c,e), e com base de níveis abaixo do considerado normal em número maior de amostras de fígado, nos Estados do Ceará e Piaúí, sugerindo a ocorrência da deficiência de zinco, mas sob forma sub-clínica, pois os históricos e estudos clínico-patológicos não indicavam a ocorrência desta deficiência (Moraes 1998), e ainda no Estado do Rio de Janeiro no município de Seropédica (Moraes et al. 1999). No Estado de Mato Grosso, no município de Diamantina, as análises de forrageiras indicam a ocorrência de deficiência de zinco (Costa et al. 1992).

Baixos valores de manganês em amostras de fígado foram constatados com maior incidência, somente nos Estados do Rio de Janeiro (Sul), do Espírito Santo (Norte), do Ceará (Serra da Ibiapaba) e do Amapá, o que sugere a ocorrência de deficiência de manganês, mas sob forma sub-clínica, pois os históricos e estudos clínico-patológicos não indicavam a ocorrência desta deficiência (Moraes 1998), e ainda no nordeste de Minas Gerais (Moraes et al. 1999). Foram encontrados baixos valores de manganês em amostras de fígado de bovinos afetados pela "doença do peito inchado", doença crônica de etiologia ainda não esclarecida no Estado de Santa Catarina (Tokarnia et al. 1989).

Em relação ao manganês há, no Pantanal Mato-grossense, verificações de valores elevados em amostras de fígado, de acordo com os autores com perigo de toxidez (Brum e al. 1987b, Pott et al. 1989a,c,e) e valores altos em amostras de fígado no Estado do Rio Grande do Sul nos municípios de Cacequi, Itaquí e Uruguaiana (Moraes et al. 1999).

Em relação ao selênio os dados continuam escassos, insuficientes para se saber qual a importância da deficiência deste elemento em bovinos e ovinos no Brasil. Somente em uma ocasião foi diagnosticada a miopatia nutricional em bezerros, no Estado do Rio Grande do Sul (Barros et al. 1988). Além dos poucos levantamentos à base de análises de amostras de sangue e de fígado, foram ainda realizados alguns trabalhos experimentais sobre o efeito da suplementação com selênio ou selênio combinado com vitamina $\mathrm{E}$ na retenção de placenta, na gestação e fertilidade de vacas e no desenvolvimento e crescimento de bovinos, no Estado de São Paulo (Lucci et al. 1984c, 1985, 1986a,b, 1987, Zanetti et al. 1984, Rosa et al. 1985a), no Estado de Minas Gerais (Vasconcelos et al. 1989) e no Estado do Rio Grande do Sul (Santiago 1985, 1986a,b,c).

Ao analisar dados da literatura sobre o estudo de deficiências e desequilíbrios minerais em animais, é preciso lembrar que esses estudos devem ser conduzidos de modo a contemplarem o maior número possível de ângulos: animal-planta-solo, dando ênfase ao animal; "quanto mais próximo ao animal" (exame do rebanho, análises químicas, experimentação), menores são os riscos de erros na interpretação dos dados. Gostaríamos de registrar que o procedimento mais seguro no diagnóstico de deficiências e desequilíbrios minerais é o exame do rebanho, sob o ponto de vista clínico-patológico, complementado por análises químicas de tecido animal e/ou experimentação. A interpretação de dados obtidos por análises químicas de pastagem e solo, em geral, é difícil. Em amostras de pastagens, os dados encontrados em relação a alguns dos elementos somente têm valor relativo, pois devem ser confrontados com os de outros minerais da mesma amostra, que podem ter interferência na sua assimilação pelo animal. Além disso, em muitas regiões a coleta da amostra representativa de forragem, ou seja, daquilo que os animais ingerem, é impossível. Há ainda a considerar as variações dos teores dos elementos nas amostras da mesma pastagem, nas diferentes épocas do ano, variações essas que, relativamente à maioria dos elementos, são bastante grandes (são muito maiores que as do material proveniente do animal). Por isso, as amostras têm que ser coletadas em número elevado e vários minerais têm que ser analisados. Também devem ser levadas em consideração a quantidade do mineral que é assimilável pelo animal, a contaminação das amostras pelo solo e a circunstância de os animais ingerirem alguma quantidade de terra juntamente com a pastagem. A interpretação dos resultados das análises do solo torna-se ainda mais difícil, em relação à maioria dos elementos, visto que, além de interferências, deve ser considerado que nem todas as quantidades de um mineral existentes no solo são aproveitáveis pelas plantas, por haver diversos fatores influenciando a sua assimilação, como por exemplo, o pH do solo e a forma química do elemento no solo. Desta maneira, análises de pastagem ou ainda análises de solo sempre constituem apenas um complemento. (Tokarnia et al. 1988)

\section{REFERÊNCIAS}

Barros C.S.L., Barros S.S., Santos M.N. \& Metzdorf L.L. 1988. Miopatia nutricional em bovinos no Rio Grande do Sul. Pesq. Vet. Bras. 8(3/4):51-55.

Bondan E.F., Riet-Correa F. \& Giesta S.M. 1991. Níveis de cobre em fígados de bovinos no sul do Rio Grande do Sul. Pesq. Vet. Bras. 11(3/4):75-80.

Brum P.A.R., Sousa J.C., Comastri Filho J.A. \& Almeida I.L. 1987a. Deficiências minerais de bovinos na sub-região dos Paiaguás, no Pantanal Matogrossense. I. Cálcio, fósforo e magnésio. Pesq. Agropec. Bras. 22(9/10):10391048.

Brum P.A.R., Sousa J.C., Comastri Filho J.A. \& Almeida I.L. 1987b. Deficiências minerais de bovinos na sub-região dos Paiaguás, no Pantanal Mato- 
grossense. II. Cobre, zinco, manganês e ferro. Pesq. Agropec. Bras. 22(9/ 10):1049-1060.

Costa J.B.D., Wolf G., Sousa J.C. \& Costa F.P. 1992. Suplementação mineral de novilhas neloradas em solo arenoso de mata e pastagens de capim-colonião. Pesq. Agropec. Bras. 27(10):1459-1466.

Dayrell M.S., Lopes H.O.S., Sampaio I.B.M. \& Döbereiner J. 1973. Fatores a serem considerados na interpretação de valores analíticos de fósforo inorgânico no soro sanguíneo de bovinos. Pesq. Agropec. Bras. 8:43-47.

Dayrell M.S. \& Resz F. 1984. Teor de fósforo inorgânico no soro sanguíneo de vacas em lactação da região da Zona da Mata. Pesq. Agropec. Bras. 19(10):1307-1312.

Fichtner S.S., Paula A.N. \& Viana H.A. 1987. Determinação das carências minerais em bovinos no Estado de Goiás. I. Zinco, cobalto, ferro e manganês. Anais da XXIV Reunião Anual da SBZ, 26 a 31 de julho, Brasília, p. 145. (Resumo)

Guimarães A.M., Saliba E.O.S., Rodriguez N.M. \& Moreira P.K. 1992. Variação sazonal de vitamina A, macro e microelementos no capim, plasma e fígado de novilhas Nelore, criadaas em pastagens de capim braquiária (Brachiaria decumbens). Arq. Bras. Med. Vet. Zootec. 44(1):57-66.

Lisbôa J.A.N., Kuchembuck M.R.G., Kohayagawa A., Bomfim S.R.M., Santiago A.M.H. \& Dutra I.S. 1996. Resultados de patologia clínica e dosagens de elementos minerais em bovinos acometidos pelo botulismo epizoótico no Estado de São Paulo. Pesq. Vet. Bras. 16(4):91-97.

Lucci C. S., Moxon A.L., Zanetti M.A., Fukushima R.S., Schalch E. \& Pettinati R.L. 1984a. Selênio em bovinos leiteiros no Estado de São Paulo. I. Níveis de selênio em soros sanguíneos . Revta Fac. Med. Vet. Zootec., USP, 21(1):6570 .

Lucci C. S., Moxon A.L., Zanetti M.A., Franzolin Neto R. \& Maracomini D.G. 1984 b. Selênio em bovinos leiteiros do Estado de São Paulo. II. Níveis de selênio nas forragens e concentrados. Revta Fac. Med. Vet. Zootec., USP, 21(1):71-76.

Lucci C.S., Zanetti M.A., Schalch E., Pettinati R.L. \& Andrade A.M.L. 1984c. Selênio em bovinos leiteiros no Estado de São Paulo. III. Suplementação de selênio no município de Descalvado . Revta Med. Vet. Zootec.,USP, 21(2):129-133.

Lucci C. S., Zanetti M.A., Schalch E. \& Pettinati R.L., Franzolin Neto R., Ostronoff S., Campos D.M., Silva A.G. \& Andrade A.M.L. 1985. Suplementação de selênio para bovinos leiteiros. Anais da XXII Reunião Anual da SBZ, Camboriú, SC, Resumo 073.

Lucci C. S., Zanetti M.A., Franzolin Neto R., Schalch E. \& Silva A.G. 1986a. Selênio em vacas leiteiras do Estado de S.Paulo. Suplementação no município de São João da Boa Vista. Revta Soc. Bras. Zootec. 15(6):447-451.

Lucci C. S., Zanetti M.A., Schalch E. \& Pettinati R.L.\& Campos D.M. 1986 b. Selênio em bovinos leiteiros do Estado de São Paulo. Suplementação no município de São Carlos. Arq. Bras. Med. Vet. Zootec. 38(4):589-597.

Lucci C. S., Schalch E., Zanetti M.A., Pettinati R.L \& Ostronoff S. 1987. Selênio em bovinos de leite em Itirapina, Estado de São Paulo. Pesq. Agropec. Bras. 22(6):653-656

Mello M.A., Ferreira P.M., Lucio N.F., Silva J.M.L., Marques D.C. 1973. Hepatose dietética em suinos associada a deficiência de selênio na dieta. Anais do Encontro de Pesquisa da Escola de Veterinária da UFMG, 8, p.9. Cit. por Ortolani E.L. Selenium deficiency in domestic animals of Brazil. Impresso de 4 p. sem data e procedência.

Moraes S.S. 1986. Untersuchungen zu Abhängigkeiten der Zink-, Manganund Selengehalte in Lebern von Rindern aus ausgewählten Regionen Brasiliens. Dissertation, Hannover. 146 p.

Moraes S.S. 1998. Avaliação das concentrações de ferro, manganês e ferro no fígado de bovinos e ovinos de várias regiões do Brasil. Pesq. Vet. Bras. 18(3/4):107-110.

Moraes S.S., Silva G.N. \& Döbereiner J. 1994. Microelementos minerais e a "cara inchada" dos bovinos. Pesq. Vet. Bras. 14(1):25 - 33.

Moraes S.S., Tokarnia C.H. \& Döbereiner J. 1999. Deficiências de microelementos em bovinos e ovinos em algumas regiões do Brasil. Pesq. Vet. Bras. 19(1):19-33.
Penna A.P., Virgens N.C., Bautista A.R.P.L., Rodrigues F.M., Silva W.G., Costa J.B. \& Suzart J.C.C. 1983. Interação da deficiência de zinco no elo forrageirabovino, no município de Ipirá - Bahia. Anais da XX Reunião Anual da SBZ, Pelotas, RS. (Resumo)

Pilati C., Barros C.S.L., Guidice J.C. \& Bondan E. 1990. Intoxicação crônica por cobre em ovinos. Hora Vet, Porto Alegre, 9(54):31-34.

Pott E.B., Brum P.A.R., Almeida I.L., Comastri Filho J.A. \& Dynia J.F. 1987. Nutrição mineral de bovinos de corte no Pantanal Mato-grossense. I. Levantamento de macronutrientes na Nhecolândia (parte central). Pesq. Agropec. Bras. 22 (9/10):1093-1109.

Pott E.B., Almeida I.L., Brum P.A.R., Comastri Filho J.A., Pott A. \& Dynia J.F. 1989a. Nutrição mineral de bovinos de corte no Pantanal Mato-grossense. 2. Micronutrientes na Nhecolândia (parte central). Pesq. Agropec. Bras. 24 (1):109-126.

Pott E.B., Pott A., Almeida I.L., Brum P.A.R., Comastri Filho J.A., \& Tullio R.R.. 1989b. Nutrição mineral de bovinos de corte no Pantanal Mato-grossense. III. Levantamento de macronutrientes no Baixo Piquiri. Pesq. Agropec. Bras. 24 (11):1361-1368.

Pott E.B., Brum P.A.R., Pott A., Almeida I.L., Comastri Filho J.A. \& Tullio R.R.. 1989c. Nutrição mineral de bovinos de corte no Pantanal Mato-grossense. IV. Levantamento de micronutrientes no Baixo Piquiri. Pesq. Agropec. Bras. 24 (11):1369-1380.

Pott E.B., Brum P.A.R., Almeida I.L., Comastri Filho J.A. \& Pott A. 1989d. Nutrição mineral de bovinos de corte no Pantanal Mato-grossense. V. Levantamento de macronutrientes na sub-região de Aquidauana. Pesq. Agropec. Bras. 24 (11):1381-1395.

Pott E.B., Comastri Filho J.A., Almeida I.L., Brum P.A.R. \& Pott A. 1989e. Nutrição mineral de bovinos de corte no Pantanal Mato-grossense. VI. Levantamento de micronutrientes na sub-região de Aquidauana. Pesq. Agropec. Bras. 24 (11):1381-1395.

Ribeiro L.A.O., Rodrigues N.C. \& Nardin N.S. 1985. Intoxicação crônica pelo cobre em ovinos no Rio Grande do Sul: histologia e toxicologia Anais IX Congr. Est. Med. Vet., Santa Maria, RS, p. 71-72. (Resumo)

Ribeiro L.A.O., Pires Neto J.A.S., Rodrigues N.C. \& Fallavena C.B. 1995. Intoxicação crônica por cobre em ovinos mantidos em pomar de macieiras. Pesq. Vet. Bras. 15(1):15-17.

Riet-Correa F., Oliveira J.A., Giesta S., Schild A.L. \& Méndez M.C. 1989. Intoxicação crônica por cobre em ovinos no Rio Grande do Sul. Pesq. Vet. Bras. 9(3/4):51-54.

Riet-Correa F., Bondan E.F., Méndez M.C., Moraes S.S. \& Concepción M.R. 1993. Efeito da suplementação com cobre e doenças associadas à carência de cobre em bovinos no Rio Grande do Sul. Pesq. Vet. Bras. 13(3/4):45-49.

Rosa L.C.A., Siqueira M.M., Andrade P., Oliveira M.D.S. \& Sampaio A.A.M. 1985a. Efeito do selênio e vitamina "E" sobre a retenção da placenta do gado leiteiro. Ars Vet., Jaboticabal, 1(1):117-122.

Rosa L.C.A., Andrade P., Fernandes L.B., Andrade A.T. \& Sampaio A.A.M. 1985b. Efeito do selênio e vitamina "E" sobre o crescimento de novilhos e novilhas da raça Nelore mantidos em pastagens. Revta Soc. Bras. Zootec. $14(1): 14-18$.

Santiago C.M. 1985. Estudo da influência do uso da emulsão de selêniotocoferol no desenvolvimento ponderal dos bezerros de raça de corte no RS, Brasil. Hora Vet., Porto Alegre, 5(26):28-31.

Santiago C.M. 1986a. Estudo da influência do uso da emulsão de selêniotocoferol nas vacas de corte em gestação no Rio Grande do Sul, Brasil. Hora Vet., Porto Alegre, 6(31):23-25.

Santiago C.M. 1986b. Estudo do efeito da emulsão de selênio-tocoferol na fecundidade de vacas de corte no Rio Grande do Sul, Brasil. Hora Vet., Porto Alegre, 6(32):13-15.

Santiago C.M. 1986c. Estudo do crescimento dos bezerros nascidos sob o efeito da aplicação da emulsão de selênio-tocoferol nas vacas gestantes. Hora Vet., Porto Alegre, 6(34): 25-27.

Sousa J.C., Nicodemo M.L.F. \& Darsie G. 1989. Deficiências minerais em bovinos de Roraima, Brasil. V. Cobre e molibdênio. Pesq. Agropec. Bras. 24(12):1547-1554. 
Tokarnia C.H. \& Döbereiner J. 1976. Doenças causadas por deficiências minerais em bovinos em regime de campo no Brasil, p. 298-308. In: Simpósio Latino-Americano sobre Pesquisa em Nutrição Mineral de Ruminantes em Pastagens, Belo Horizonte, Minas Gerais.

Tokarnia C.H. \& Döbereiner J. 1978. Diseases caused by mineral deficiencies in cattle raised under range conditions in Brazil, p. 163-169. In: Conrad J.H. \& McDowell L.R. (ed.) Latin American Symposium on Mineral Nutrition Research with Grazing Ruminants, Belo Horizonte, Brazil.

Tokarnia C.H. \& Döbereiner J. 1998. Sobre o "ronca”, doença de etiologia obscura em bovinos, caracterizada por respiração ruidosa. Pesq. Vet. Bras. 18(3/4):93-98.

Tokarnia C.H., Canella C.F.C., Guimarães J.A. \& Döbereiner J. 1968. Deficiências de cobre e cobalto em bovinos e ovinos no nordeste e norte do Brasil. Pesq. Agropec. Bras. 3:351-360.

Tokarnia C.H., Guimarães J.A., Canella C.F.C. \& Döbereiner J. 1971. Deficiênci- as de cobre e cobalto em bovinos e ovinos em algumas regiões do Brasil. Pesq. Agropec. Bras. 6:61-77.

Tokarnia C.H., Döbereiner J. \& Moraes S.S. 1988. Situação atual e perspectivas da investigação sobre nutrição mineral em bovinos no Brasil. Pesq. Vet. Bras. 8(1/2):1-16.

Tokarnia C.H., Gava A., Peixoto P.V., Stolf L. \& Moraes S.S. 1989. A “Doença do peito inchado“ (edema da região esternal) em bovinos no Estado de Santa Catarina. Pesq. Vet. Bras. 9 (3/4):73-83.

Vasconcelos J.L.M., Silva H.M., Reis R.B. \& Raslam K.G. 1989. Retenção de placenta em gado leiteiro. I.-Efeito da administração de selênio sobre a incidência de retenção de placenta. Arq. Bras. Med. Vet. Zootec. 41(4):315322.

Zanetti M.A., Lucci C.S. \& Meirelles G.J.R 1984. Selênio em bovinos leiteiros no Estado de São Paulo. V. Suplementação de selênio para vacas em fase final de gestação. Revta Fac. Med. Vet. Zootec.USP, 21(2):141-145. 